\title{
A REPRESENTAÇÃO DOS POVOS INDÍGENAS DO BRASIL NO LIVRO DIDÁTICO DE HISTÓRIA PROJETO ARARIBÁ
}

\section{REPRESENTATION OF INDIGENOUS PEOPLES OF BRAZIL IN HISTORY TEXTBOOK}

\author{
CARLO GUIMARÃES MONTI ${ }^{1}$ \\ CHRISLAINE JANAÍNA DAMASCENO ${ }^{2}$
}

\begin{abstract}
RESUMO
Este estudo visa analisar como se insere a representação dos povos indígenas no livro didático do $7^{\circ}$ ano do Ensino Fundamental. Explorando a discussão racial do século XIX até o século XX no Brasil e suas influências no discurso de construção da identidade do povo brasileiro formado por indígenas, negros e brancos. Pretende-se detectar permanências no século XXI por meio da análise de documentos sobre a educação brasileira, como o Parâmetro Curricular Nacional (com o tema transversal Pluralidade Cultural) e das Leis $n^{\circ} 10.639 / 03$ e $n^{\circ}$ 11.645/08, que propõe a valorização da diversidade étnico-racial, assim como o estudo das contribuições dos negros e indígenas na história do Brasil e na formação da nação. $\mathrm{O}$ artigo tem por fim verificar se as mesmas propostas estão sendo aplicadas no que tange à temática indígena, conforme a legislação, no livro didático Projeto Araribá, do $7^{\circ}$ ano do Ensino Fundamental.
\end{abstract}

PALAVRAS-CHAVE: Povos Indígenas; Educação; Livro Didático.

\begin{abstract}
This study aims to examine how is inserted the representation of indigenous people in the textbook of the 7th year of elementary school. Exploring the racial discussion of the XIX century until the XX century in Brazil and its influences on the discourse of the construction of identity of the Brazilian people formed by indigenous, black and white people by through the appreciation of the three races, detecting continuities in the XXI century in the elaboration of official documents on the Brazilian education on Parameter National Curricular, transversal theme Cultural Plurality and law No. 10.639/03, modified by law No. 11,645/08, that proposes the enhancement of ethnic and racial diversity and the study of the contributions of blacks and indigenous people in the Brasil history and their formation, verifing if this proposals are being applied in the ethnic theme in the textbook Araribá project proposed for the 7 th year of elementary school.
\end{abstract}

KEYWORDS: Indigenous people; Education; Textbook.

\footnotetext{
${ }^{1}$ Universidade Federal do Sul e Sudeste do Pará - carlogmonti@gmail.com

${ }^{2}$ Universidade Estadual Paulista-UNESP - chrisdamasceno@ hotmail.com
} 


\section{Introdução}

A educação brasileira tem, historicamente, sido marcada como um espaço em que perduram desigualdades sociais e raciais. A constatação desta situação, especialmente na década de 1980, durante o processo de redemocratização do país, pressionou o Estado com uma nova forma de atuação política dos brasileiros ${ }^{3}$ por meio de movimentos sociais, trazendo novas formas de ação e reivindicação política, especialmente as de caráter identitário.

Tanto na Constituinte quanto na elaboração da nova Lei de Diretrizes e Bases da Educação (lei n.9394/96), houve a participação marcante da militância negra nos anos 1980. No entanto, [...] nem a Constituição de 1988 nem a LDB incluíram, de fato, as reivindicações desse movimento em prol da educação. Os debates em torno da questão racial realizados entre o Movimento Negro e os parlamentares revelam um processo de esvaziamento do conteúdo político de tais reivindicações. Essas acabam sendo inseridas de maneira parcial e distorcidas nos textos legais. Compreendendo esse processo, é possível entender o significado genérico do art.26 da LDB, que só foi revisto e alterado quando ocorre a sanção da lei n. 10639/03 (obrigatoriedade do ensino de História da África e das culturas afro-brasileiras nas escolas públicas e particulares dos ensinos fundamental e médio) (GOMES, 2013, p. $113)$.

Em respostas a essas exigências o Ministério da Educação elaborou os Parâmetros Curriculares Nacionais (PCN's), em 1995, tratando a questão da diversidade de maneira generalizante, sendo, somente em 1996, adicionado ao texto original o tema transversal Pluralidade Cultural, "[...] o qual apresentou um posicionamento explícito de superação do racismo e da desigualdade racial na educação" (GOMES, 2013, p. 114). No entanto, somente a partir de 2003 é dedicada maior atenção a esse debate ${ }^{4}$ :

No tocante a educação, é nesse contexto que, finalmente, é sancionada a lei n.10.639, em janeiro de 2003, alterando a lei n.9.394/96- Lei de Diretrizes e Bases da Educação. Em 2004, o Parecer CNE/CP 03/2004 e a Resolução CNE/CP 01/2004 são aprovados pelo Conselho Nacional para a Educação das Relações étnico-Raciais e para o ensino de História e Cultura Afro-Brasileira e Africana. Em 2009, é lançado pelo Ministério da Educação e pela Secretaria Especial de Políticas de Promoção da Igualdade Racial, o Plano Nacional de Implementação das referidas diretrizes curriculares (GOMES, 2013, p. 114).

\footnotetext{
${ }^{3}$ Representados em sua maioria por participantes do Movimento Negro que questionam o Estado, a esquerda brasileira e os movimentos sociais sobre seu posicionamento neutro e omisso diante da centralidade da raça na formação do país.

${ }^{4}$ Devem ser citadas a criação da Seppir (Secretaria Especial de Promoção da Igualdade Racial) em 2003 e da Secad (Secretaria de educação Continuada, Alfabetização e Diversidade) em 2004.
} 
Diante desse quadro, as discussões sobre diversidade começam a ocupar um lugar de destaque, gerando questões e desafios sobre como introduzir essas novas práticas indicadas pelo Ministério da Educação no ensino efetivo das escolas. Dessa maneira, surge a proposta deste artigo, com o objetivo de estudar como essas novas práticas são veiculadas no livro didático de História do "Projeto Araribá: história/organizadora" do $7^{\circ}$ ano do Ensino Fundamental II, nas narrativas e imagens das populações nativas do território brasileiro anteriores à colonização e seu desenrolar na história do Brasil.

Para alcançar o eixo central da pesquisa, será analisada a Lei $\mathrm{n}^{\circ}$ 10.639/03 alterada em 2008 pela Lei ${ }^{\circ} 11.645$ e os Parâmetros Curriculares Nacionais (PCN's) Pluralidade Cultural, no que tange a "[...] luta dos negros e dos povos indígenas no Brasil, a cultura negra e indígena brasileira e o negro e o índio na formação da sociedade nacional, resgatando as suas contribuições nas áreas social, econômica e política, pertinentes à história do Brasil." (BRASIL, 2018). Inquirindo qual o seu impacto na elaboração dos livros didáticos, no que cerne à diversidade étnico-racial indígena, e na questão política da hierarquização de poderes. Será possível perceber se há relação entre a teoria e os métodos adequados ao Ensino Fundamental, divulgadas pelo Governo Federal e Estadual, com o que é praticado no livro didático escolhido nas escolas e repassado aos alunos para formação de seus referenciais sobre a temática indígena no Brasil.

Pretende-se, através das análises, compreender se existem lacunas na produção narrativa e imagética da história indígena destinada ao aluno do Ensino Fundamental. O livro didático escolhido para análise é o do $7^{\circ}$ ano do Ensino Fundamental II. Projeto araribá: história/organizadora Editora Moderna, PNLD 2014/2015/2016-FNDE Ministério da Educação, tendo em vista, que "Ao longo da história brasileira, foram muitas as lutas travadas pelas populações indígenas no esforço de preservar sua integridade física e cultural no contato com a sociedade envolvente." (SILVA, 1995, p. 408).

Portanto, é fundamental o estudo dos manuais didáticos oferecidos aos alunos, dado que são eles os responsáveis pela formação das representações sociais e da imagem acerca dos grupos discriminados, sob a ótica interdisciplinar da aproximação entre história, antropologia, sociologia e ciências políticas, abrindo-se espaço para considerar as tensões do universo cultural e simbólico, constantemente reordenados nos processos históricos (ABREU; SOIHET, 2013, p. 23).

Utilizar o livro didático como fonte para se compreender as culturas da memória possibilita problematizar sobre a trajetória do conhecimento histórico (BECHIER; SILVA, 
2019, p. 5), pois esse material demonstra como os acontecimentos históricos são lembrados em cada Nação. Dessa forma, a análise dos livros didáticos possibilita que se defina quais são os discursos validados como verdadeiros em uma sociedade demonstrando também o caráter político da construção da memória, uma vez que, são propagadores da representação do passado e da formação de uma identidade nacional (BECHIER; SILVA, 2019, p. 11-12). Trabalhamos com um conceito de representação, “[...] forma de conhecimento do senso comum, situada na interface do psicológico e do social, do individual e do coletivo, é uma construção, ao mesmo tempo produto e processo de uma atividade de apropriação da realidade." (SCHMIDT; CAINELLI, 2010, p. 84.

Por isso, historiadores como Jör Rüssen acreditam que as pesquisas históricas devam ser aplicadas, o mais breve possível, aos livros didáticos. Os materiais didáticos estão inseridos, tanto na elaboração quanto na aplicação, das estruturas e métodos do seu tempo, por isso, analisar seu emprego no ensino é um exercício bastante complexo necessitando que se atente para a "[...] seleção dos conteúdos, linguagem utilizada, correntes teóricas envolvidas na concepção da obra, metodologia adequada na formulação de textos e atividades, sequência e forma de apresentação de conteúdos" (FRANCO; TRUBILIANO, 2015, p. 28). Além de consagrado em nossa cultura escolar, o livro tem "[...] assumido a primazia entre os recursos didáticos utilizados na grande maioria das salas de aula do Ensino Básico [...]” (SILVA, 2012, p. 806). Por esse motivo, os discursos inseridos nesse material tomam formas cada vez mais consistentes no processo de ensino e aprendizagem e o mesmo acaba se tornando um dos mais usuais e importantes condutores do conhecimento histórico escolar.

Longe de ser uma produção exclusiva do autor, o livro didático sofre a influência de vários profissionais na sua escrita e criação. Por esse motivo, deve ser estudado como um produto cultural inserido na lógica capitalista, “[...] como uma mercadoria ligada ao mercado editorial; didaticamente, como suporte de conhecimento e de métodos de ensino; e, politicamente, como um veículo de valores ideologias e comportamentos" (FRANCO; TRUBILIANO, 2015, p. 30). Devido à complexidade de criação dessa obra que se caracteriza por diversos sujeitos em sua produção, circulação e consumo é que esse material pode assumir múltiplas funções de acordo com as condições do lugar e momento de sua produção e de sua utilização em sala de aula.

Nesse sentido é que está a relevância desse estudo, uma contribuição ao docente para que os professores problematizem estes materiais e não o usem como depositários de 
verdades absolutas, utilizando-os como um material adicional e não como sua única ferramenta de trabalho.

Sobre esses paradoxos formais acerca da questão indígena é que buscaremos localizar o momento em que essa temática entra em cena, assim como, os elementos que permitem que ela se torne cada vez mais objeto de discussão dentro da disciplina escolar de História.

\section{As propostas de ensino e como elas se articulam no tema transversal Pluralidade Cultural e na Lei ${ }^{\circ} 11.645 / 08^{5}$}

A análise do tema transversal Pluralidade Cultural presente nos Parâmetros Curriculares Nacionais, da Lei 10.639/03 e 11.645/08, busca identificar quais são as propostas do governo para se trabalhar a diversidade e detectar como essa questão é elaborada na redação dos documentos mencionados, verificando quais tradições históricas são utilizadas, com a finalidade de constatar qual conhecimento histórico a escola está produzindo.

Nos anos 90 a renovação curricular retira os Estudos Sociais das escolas, substituindo-o pelas disciplinas de Geografia e História. Essas medidas não foram específicas do Brasil, ocorreram também em outros países do Mercosul, Portugal e Espanha, que adotaram a mesma metodologia pedagógica pautada em uma lógica de mercado, onde a quantidade de conhecimento e as maneiras de dominar a informação vindas de diferentes meios de comunicação são valorizadas frente à uma economia globalizada (BITTENCOURT, 2011, p. 107).

Em meio à política de globalização, a Lei n 9.394, de 20 de Dezembro de 1996 (LDB), é aprovada no Brasil a partir das pressões dos movimentos sociais, abrindo o diálogo para a discussão dos temas de diversidade cultural e pluralidade étnica. O texto propõe a construção de uma igualdade baseada na diversidade, procurando adequar a educação do país aos princípios da Constituição de 1988 e à Comissão Internacional sobre Educação para o Século XXI da Organização das Nações Unidas para Educação, Ciência e Cultura-UNESCO.

Como extensão da Lei de Diretrizes e Bases da Educação Nacional, os Parâmetros Curriculares Nacionais são criados e, mesmo não sendo normativos, inserem-se no cotidiano escolar como instrumento legal, seguido por gestores e professores. Nestes, as questões da diversidade foram estabelecidas como temas transversais, que deveriam ser trabalhados de

\footnotetext{
${ }^{5}$ A referência a Lei $n^{\circ} 11.645 / 08$ se dá pelo fato dela abarcar também a Lei n ${ }^{\circ} 10.639 / 03$.
} 
maneira ideal, tendo as disciplinas como meio e a transversalidade como fim. Isto posto, ao se optar pelo tema Pluralidade Cultural todas "as disciplinas devem envolver-se e direcionar seus esforços para a compreensão e valorização da diversidade etnocultural, apresentando riquezas e contrastes dessa realidade, combatendo preconceitos e discriminações" (NETO, 2003, p. $67)$.

Para além do conhecimento dos diferentes grupos sociais, há um projeto maior enfatizado em todo documento que coloca a diversidade como "traço fundamental na construção de uma identidade nacional" (NETO, 2003, p. 121). Voltamos, assim, à associação presente desde o século XIX do ensino, em especial o de História, com a constituição da identidade nacional, atrelado ao discurso de que "apresentando heterogeneidade notável em sua composição populacional, o Brasil desconhece a si mesmo",

[...] a cidadania deve preocupar-se necessariamente com as diversidades existentes na sociedade, uma das bases concretas em que se praticam os preceitos étnicos. É a ética que norteia e exige de todos - da escola e dos educadores em particular-, propostas e iniciativas que visem à superação do preconceito e da discriminação. A contribuição da escola na construção da democracia é a de promover os princípios éticos de liberdade, dignidade, respeito mútuo, justiça e equidade, solidariedade, diálogo no cotidiano; é a de encontrar formas de cumprir o princípio constitucional de igualdade, o que exige sensibilidade para a questão da diversidade cultural e ações decididas em relação aos problemas gerados pela injustiça social (BRASIL, 1997, p. 129).

Em uma primeira impressão, seguir a direção apontada pelos PCN's parece ser a forma "ideal" de se trabalhar o tema da diversidade etnocultural. Contudo, o documento é escrito sob uma perspectiva universalista de educação e de políticas educacionais, é uma seleção das propostas da Organização das Nações Unidas (ONU). A questão racial permeia o discurso da pluralidade cultural sem apresentar em suas recomendações métodos contundentes de superação do racismo e da desigualdade racial na educação. As propostas apostam na enumeração de conteúdo, acreditando que a inserção de "temas sociais" transversalizando o currículo consiga abarcar a reflexão e compreensão sobre impasses que dizem respeito a posicionamentos políticos, ideológicos, preconceitos, discriminação, racismo e que vão ao encontro do imaginário social e pedagógico (GOMES, 2007, p. 116). Assim sendo, a discussão do tema da diversidade vai além de listagens conteudistas, pois entram em confronto com as práticas e com o imaginário racial presente na estrutura e no funcionamento da educação brasileira desde o século XIX, tais como o mito da democracia racial, o racismo ambíguo, a ideologia do branqueamento e a naturalização das desigualdades raciais. 
Nos Parâmetros Curriculares Nacionais de 1997 e 1998 é notável o alinhamento às abordagens anunciadas na década de 1970 na França e difundidas no Brasil nos anos 90. Há a ênfase na experiência coletiva herdada do marxismo característico no Brasil dos anos 80 através do uso de "sujeito histórico", da micro-história com o uso de escalas e das três gerações dos Annales ao adotar a noção ampliada de fonte, a interdisciplinaridade, novos tempos, durações e a história do cotidiano (FREITAS, 2013, 190).

A maior parte das propostas curriculares baseia-se em uma história social ou sócio-cultural. Essa opção é justificada pelo uso de conceitos chaves como cultura, trabalho, organização social, relações de poder e representações, quebrando, dessa maneira, a hegemonia da História Política, estruturada unicamente por meio da cronologia e da periodização clássica.

Em conformidade com as mesmas tradições historiográficas presente nos PCN's, a determinação da inclusão de História e Cultura Afro Brasileira e Indígena nos currículos da educação básica por determinação das Leis 10.639/03 e 11.645/08, busca transformar o foco etnocêntrico dos mesmos e ampliar este horizonte para a diversidade étnica, histórica, cultural, social e econômica em nosso país (FONTENELE, 2015, p. 3).

Essa política educacional atribui ao ensino de história o papel de formar um novo cidadão, capaz de compreender a história do país e do mundo como resultante de múltiplas memórias originárias da variedade das experiências humanas, contrapondo-se à memória dominante de um passado homogêneo. Assim, a Lei $\mathrm{n}^{\circ} 10.639 / 03$, alterada pela Lei $\mathrm{n}^{\circ}$ 11.645/08, incide a favor de rupturas com uma história autocentrada no nacional, na Europa, na religião cristã e na cultura branca. A alteridade e o respeito às diferenças constituem-se, desta maneira, em pilares centrais na formação das identidades das novas gerações e nas finalidades do ensino da história (SIMAN, 2005, p. 352).

Alteridade que deve ser problematizada na elaboração da Lei $\mathrm{n}^{\circ} 10.639 / 03$, que enxerga o "outro" em uma lógica dualista de contrário ao "branco", logo, o negro: "convivem, no Brasil, de maneira tensa, a cultura e o padrão estético negro e africano e um padrão estético e cultural branco europeu" (BRASIL, 2004, p. 14). A lei que pretende a promoção da igualdade racial relega aos índios e asiáticos posição de coadjuvantes em relação a "negros" e "brancos". Sendo esses, em alguns casos, citados como "outras" culturas ou "outros" povos, e, na maioria das vezes, simplesmente excluídos da política de reparação, de reconhecimento e valorização proposta pelo governo: 
O artigo 26-A, acrescentado na LDB (9.394/96), incentiva não apenas a inclusão de novos conteúdos, mas pretende uma reparação social do modelo de desenvolvimento excludente adotado ao longo da história no Brasil. Exige, acima de tudo, que sejam repensadas e discutidas as relações étnicas, sociais, pedagógicas, procedimentos de ensino, objetivos da educação e condições de aprendizagem. Porém, mesmo com a alteração feita em 10 de março de 2008 pela Lei $n^{\circ} 11.645$, tornando obrigatório o estudo da história e cultura afro-brasileira e indígena, continua preterindo a história indígena, não discorrendo sobre suas contribuições, importância e valorização na formação do Brasil. Devemos, portanto, considerar as lacunas da Lei $\mathrm{n}^{\circ} 11.645 / 08$, que pretende corrigir injustiças, eliminar discriminações e promover a inclusão social de uma parcela social em detrimento de outras, propondo tratamento igual entre as diferentes etnias e trabalhando com categorias como “minorias" para negros, indígenas e asiáticos e "classe dominante" para brancos.

Ainda que com seus pontos falhos, muitas vezes contraditórios, não se deve desconsiderar o avanço da implementação da Lei 11.645/08 para amadurecer as discussões sobre o espaço no currículo escolar para a história indígena, privilegiada neste estudo. Para mudarmos a maneira de se relacionar com a temática indígena nas estruturas estatais é preciso ter em mente a abordagem antropológica sobre as populações não ocidentais, principalmente as nativas da América, que vigorou por muito tempo e fundamentou a produção historiográfica. A mudança antropológica na forma de se entender as sociedades indígenas é primordial para a compreensão da diferença e da singularidade de interpretações dos documentos oficiais sobre esse tema. Para amenizar tais rupturas, a Lei 11.645/08 precisaria ser implantada para inserir as especificidades dessa população no currículo e nos materiais didáticos, para contemplar as diferenças e possibilitar uma educação das relações étnicoraciais (BARBOSA, 2011, p. 9).

A formação do aluno nas últimas décadas passou a ter como objetivo a construção de conhecimentos que valorizem as diversidades culturais. E, embora a lei reconheça a importância da luta do negro e do indígena no Brasil e prescreva o ensino dessas culturas nas escolas por meio de pesquisas teóricas e práticas, condenando a vertente eurocêntrica da história ensinada como única e soberana, faz-se necessário questionar se os livros didáticos do ensino fundamental estão habilitados e preparados segundo essas exigências para além da letra fria da lei.

\section{A análise da temática indígena no livro didático do $7^{\circ}$ ano do Ensino Fundamental}


Mesmo ciente da utilização, pelas escolas públicas do Estado de São Paulo, do material de apoio denominado Caderno do Aluno e desenvolvido para a implementação do Currículo do Estado de São Paulo, concentramos nossa atenção no livro didático, por ser ele ainda o norteador do planejamento e das atividades em sala de aula.

O Caderno do Aluno do Estado de São Paulo é um material complementar utilizado por alunos e professores e que tem como objetivo desenvolver habilidades como interpretação de texto. Os temas relacionados à nossa pesquisa são trabalhados nesses materiais também no $7^{\circ}$ ano do Ensino Fundamental. O que podemos constatar na leitura do estudo realizado por Maria Cristina Floriano Bigeli intitulado "Ensino de história e cultura indígena: os discursos do currículo São Paulo Faz Escola (2014-2017) e dos docentes de história" é a escassez de atividades sobre o tema, apenas 5, sobre a História e Cultura Indígena e que são acompanhadas de informações desatualizadas "Apesar da edição do material didático datar de 2014, a informação de que a população brasileira é formada por apenas $0,3 \%$ de indígenas já se encontra desatualizada [...]” (BIGELE, 2018, p. 98) reforçando a concepção de que essas populações habitam somente o nosso passado. De associações simplistas entre indígenas e a natureza e de "[...] generalizações que podem causar confusão na aprendizagem a respeito dos povos nativos.” (BIGELE, 2018, p. 101).

Gerando representações construídas por meio do ensino de história que levam a naturalização do passado. Em um tempo contínuo, não diferenciando acontecimentos, conjunturas e estruturas, sem um processo de ruptura com o período colonial. Os povos indígenas são vistos por meio de um passado que não rompe com as suas estruturas em um tempo linear eurocêntrico envolto pelos aspectos mais puros da colonialidade. Além de utilizarem fontes históricas de forma equivocadas e sem dar-lhes as devidas contextualizações. Podemos inferir que mesmo uma produção que se propõe nova e auxiliar aos livros didáticos, apresenta interpretações ultrapassadas e estereotipadas similares ao livro que analisamos, sendo possível, em um estudo posterior, uma análise extensa e comparativa entre esses materiais. Partindo do princípio de que o material didático é mediador da apreensão de conhecimento, facilitador de conceitos e veículo de sistemas de valores e ideologias de uma determinada época e sociedade.

As regras estabelecidas no Programa Nacional do Livro Didático (PNLD), que tem como critério de aprovação o atendimento a Lei 11.645/2008 até que ponto acabam por influenciar na construção final dos materiais? 
Devemos pontuar a expansão de uma esfera lucrativa que rodeia as obras escolares. "Livro não é apenas objeto de cultura [...] é também negócio. Mercado e cultura não se excluem" (MUNAKATA, 2012, p. 58). Além do valor cultural e social, adquirido quando se inserem no universo escolar, os manuais carregam também uma dimensão econômica e mercadológica que incide na adequação de seus conteúdos para um mercado que rende um número altíssimo de cifras por ano.

Isso só foi possível com o crescimento descomedido das políticas públicas acerca dos manuais didáticos, protagonizado, principalmente, pelo Plano Nacional do Livro Didático (PNLD). Após os livros passarem por uma intensa avaliação de seus conteúdos e organizações metodológicas, as obras aprovadas são organizadas em um documento de síntese, chamado Guia de Livros Didáticos, com resenhas das coleções consideradas aprovadas. "O guia é encaminhado às escolas, que escolhem, entre os títulos disponíveis, aqueles que melhor atendem ao seu projeto político-pedagógico" (BRUM, 2016, p. 55). Desta forma, não basta o esforço das editoras apenas pela aprovação de seus materiais no sistema de distribuição do governo federal, elas passam, ao mesmo passo, a investir em equipes de divulgadores, “[...] que tentam sensibilizar os professores para os produtos que representam [...]" (MUNAKATA, 2012, p. 62).

Em contrapartida, essa instituição de uma política avaliativa das obras utilizadas no sistema de ensino nacional proporcionou um desencadeamento de "[...] poderosos mecanismos de reajustamento e adaptação no mercado editorial" (LUCA; MIRANDA, 2004, p. 128). O setor livresco, depois de ter suas obras adequadas aos requisitos pré-estabelecidos do PNLD, tem suas vendas garantidas para o Estado, o que propicia um gradativo aumento do mercado didático e, dá suporte à um avanço descomunal dessa esfera comercial. O mercado do livro didático no Brasil é, hoje, um dos que mais rende lucros por ano para as editoras, “[...] o que lhe valeu menção no Guiness e o converteu em um dos maiores compradores de livros do mundo [...]" (GARRIDO, 2008, p. 243). É válido frisar, no entanto, que os polpudos lucros econômicos que circundam o mercado editorial acabam por desfavorecer a assertividade dos aprimoramentos que as avaliações propõem aos conteúdos históricos, já que “Os livros didáticos impulsionados, sobretudo, pelo PNLD, são responsáveis por sessenta por cento de todo o faturamento da indústria livresca no Brasil [...]”' (SILVA, 2012, p. 810).

Em um período de 10 anos analisados, o faturamento do setor de livros didáticos no Brasil, apesar da queda nas vendas, cresceu cerca de aproximadamente 46\%, 
permanecendo no topo dos rendimentos da esfera editorial durante todos os anos em que esteve presente no mercado, até o atual momento.

Os gastos do Estado com a aquisição dos livros didáticos no Brasil atingem um nível estratosférico, o que, ao mesmo passo, causa um processo de oligopolização de grandes empresas e amplia a entrada de capital estrangeiro, que passou a comprar diversos dos maiores grupos editoriais brasileiros.

Com esses dados não fica difícil perceber como essas numerosas coletividades livrescas vão influir, cada vez mais, no conteúdo veiculado pelo livro didático. Além de uma preocupação com as adequações ideológicas para que as obras sejam devidamente distribuídas aos sistemas de ensino, os materiais passam a atender uma demanda mercadológica através da qual os polpudos lucros passam a promover o crescimento do setor editorial, fazendo com que, esse ciclo de provento não seja desvinculado do Estado.

É, conquanto, a partir dessa preocupação com o capital que as faltas e erros começam a se fazer cada vez mais presentes nos materiais. Com um afrouxamento dos requisitos de avaliações das obras didáticas, passando de "obrigações" a meras "sugestões pedagógicas", as temáticas vêm tomando formas equivocadas no que diz respeito aos conteúdos concernentes à multi e a pluriculturalidade brasileira.

Nosso imaginário social sobre os índios formou-se por diferentes interpretações e julgamentos de estudiosos, viajantes portugueses e outros europeus que aqui se instalaram desde 1500. Resultado de ambiguidades e contradições, a visão do indígena está "permeada pela visão evolucionista da história das culturas, [que] continua considerando os povos indígenas como culturas em estágios inferiores, cuja única perspectiva é a integração e a assimilação à cultura global” (BARBOSA, 2011, p. 15).

Baseado nessas diferentes perspectivas, objetiva-se identificar, através do estudo das unidades 5 (Os povos pré-colombianos) e 6 (As grandes navegações e a colonização da América Portuguesa), do livro de História Projeto Araribá, do $7^{\circ}$ ano do Ensino Fundamental, se este material já está adequado à proposta educacional da Lei nº 11.645/08.

A unidade 5 (Os povos pré-colombianos) trata das populações que habitavam a América antes da chegada dos europeus e é subdivida em cinco temas: América: Terra de grandes civilizações; A civilização maia; O império Asteca; No sul da América e A civilização inca. $\mathrm{O}$ tema que deveria referir-se aos povos nativos que habitavam a região que hoje forma o Brasil seria o tema 4 (No sul da América), pela lógica do Brasil estar na América do Sul. No entanto, América do Sul no livro é composta apenas pelo Peru e Cordilheira dos 
Andes, servindo para o estudo exclusivo dos Chavín. Em todos os outros temas dessa unidade não há menção aos nativos que habitavam o território brasileiro atual.

A ausência da história dos nativos do nosso território anterior à chegada do europeu revela como os materiais didáticos ainda consideram uma interpretação de formação dos povos brasileiros e suas identidades a partir da chegada do branco e da colonização. Não estudar as populações que aqui habitavam, pressupõe que nossa formação como brasileiro inicia-se com a chegada do europeu. Antes, seguindo este pensamento, não há história para se conhecer. Essa mentalidade eurocêntrica de valorização do europeu como "civilizador" e “descobridor” presente no livro é combatida pelo PCN - Pluralidade Cultural ao afirmar que “todos os grupos sociais e étnicos têm histórias. Essas histórias são distintas entre si e também distintas do que se convencionou como história do Brasil, no singular" (BRASIL, 1997, p. 153), enfatizando a necessidade de se conhecer “[...] a presença e diferentes formas de organização social dos indígenas, em sua diversidade, no continente e em território nacional anterior a chegada dos europeus, assim como a presença de outras culturas pré-colombianas na América Latina” (BRASIL, 1997, p. 153).

A unidade 6 (As grandes navegações e a colonização da América portuguesa) está dividida em quatro temas: A expansão marítima portuguesa; A expansão marítima espanhola; A colonização portuguesa na América e a Administração da América portuguesa. O tema analisado aqui será o 3 (A colonização portuguesa na América), onde aparece pela primeira vez no livro a menção aos povos indígenas e o contato com o europeu.

O título do capítulo, "A colonização portuguesa na América", em conformidade com os PCN's, já não trabalha com os conceitos de descoberta e conquista, já que o primeiro termo ignorava a história local e o segundo implica não só em uma violência aberta, mas também na produção de novas relações de identidades sociais, como violência simbólica. Ao optar pelo termo colonização, há a tentativa de afastamento de uma visão determinista de descoberta e conquista, que transpõe um movimento de violência física e social. O termo "descoberta" é modificado por "colonização", porém o conteúdo continua referindo-se a "descoberta”, uma vez que não há no livro indicação sobre as populações existentes antes da colonização, levando a supor que a existência deste território se inicia com a chegada dos portugueses.

$\mathrm{Na}$ primeira subdivisão do capítulo percebe-se que o material trabalha com o conceito de exploradores e explorados, atribuindo ao europeu o papel de protagonistas das relações com os nativos. "Os exploradores portugueses não encontraram ouro ou pedras 
preciosas em suas primeiras incursões à América. Por essa razão, a Coroa procurou garantir seus domínios no Oriente, principalmente das lucrativas rotas de comércio nas Índias" (PROJETO ARARIBA, 2014, p. 166). Como destacado, os índios só aparecem em função do colonizador. Em uma nova perspectiva de trabalho, recomendada por Maria Regina Celestino Almeida, descarta-se a interpretação de aculturação e resistência como polos opostos, demonstrando que a colonização não significou para os índios apenas perdas e prejuízos, sendo entendida como espaço possível de sobrevivência desses grupos. Ao afirmar que "se os europeus cedo compreenderam as hostilidades entre os grupos indígenas e utilizaram-se delas em proveito próprio, a recíproca é verdadeira" (ALMEIDA, 2011, p. 28), a autora, diferentemente do livro didático, está em sincronia com a proposição do PCN"s, que argumenta transpor a dicotomia entre exploradores e explorados já que "diante da busca de homogeneização cultural que se tentou impor, diferentes grupos no Brasil tiverem de resistir, recolocar-se, recriar-se, de forma ativa em diferentes momentos da história" (BRASIL, 1997, p. 154).

A interação entre indígenas e portugueses aparece no livro, primeiramente, como pacífica, modificada posteriormente pela escravização dos nativos, reforçando o dualismo entre conquistadores e conquistados e dominantes e dominados. Ao tratar da guerra entre os dois povos, o conceito de resistência deveria ser abordado, o que não ocorre, pois, a guerra, segundo o material didático, serviu para dizimar a população nativa que se isolou no interior do território. Essa interpretação homogênea de dizimação e isolamento ausenta os indígenas de participação histórica no período da colonização.

Somente na página 172 do livro é feita uma breve descrição das populações indígenas no período da colonização. A temática só é ampliada em uma sessão posterior ao capítulo, denominada "Em Foco", que, nesta unidade, tem como título "Os povos indígenas no Brasil”. A impressão que se tem é de uma tentativa de atender às modificações da Lei 11.645/08 sem alterar o conteúdo principal do livro, que, como analisado, diverge das modificações propostas pela mesma, que afirma em seu $1^{\circ}$ parágrafo, do Artigo 26-A:

$\S 1^{\circ} \mathrm{O}$ conteúdo programático a que se refere este artigo incluirá diversos aspectos da história e da cultura que caracterizam a formação da população brasileira, a partir desses dois grupos étnicos, tais como o estudo da história da África e dos africanos, a luta dos negros e dos povos indígenas no Brasil, a cultura negra e indígena brasileira e o negro e o índio na formação da sociedade nacional, resgatando as suas contribuições nas áreas social, econômica e política, pertinentes à história do Brasil (BRASIL, 2009, p. 1). 
Com a mesma finalidade de ampliação do conhecimento e valorização da diversidade, o tema transversal Pluralidade Cultural propõe novas maneiras de se trabalhar a questão indígena dentro do currículo escolar, através de diferentes fontes, como imagens, músicas e textos acadêmicos.

O livro, no propósito de atender a essas exigências, traz como primeiro tópico, intitulado "Um caldo de culturas", na sessão "Em Foco", a letra da música Pindorama:

\author{
Pindorama, Pindorama é o Brasil antes de Cabral \\ Pindorama, Pindorama é tão longe de Portugal \\ Fica além, muito além do encontro do mar com o céu \\ Fica além, muito além dos domínios de Dom Manuel \\ Vera Cruz, Vera Cruz quem achou foi Portugal \\ Vera Cruz, Vera Cruz atrás do Monte Pascoal \\ Bem ali Cabral viu, dia vinte e dois de abril \\ Não só viu, descobriu toda terra do Brasil \\ Pindorama, Pindorama, mas os índios já estavam aqui \\ Pindorama, Pindorama já falavam tudo em tupi \\ Só depois vêm vocês que falavam tudo em português \\ Só depois com vocês, nossa vida mudou de uma vez [...] \\ A Álvares Cabral, a El rei Dom Manuel \\ Ao índio do Brasil e ainda a quem me ouviu \\ Vou dizer descobri, o Brasil tainterinho na voz \\ Quem quiser vem ouvir Pindorama ta dentro de nós [...] (PROJETO \\ ARARIBA, 2014, p. 172).
}

A explicação que acompanha a música consiste em "[...] um diálogo cantado sobre a fundação de nossa nacionalidade e a formação do povo brasileiro. Pindorama era o nome dado ao Brasil pelos índios Tupi” (PROJETO ARARIBA, 2014, p. 173). Prosseguindo, "Pindorama acontece no canto, se realiza na fala. Os indígenas, quando gritam sua miséria e seu esquecimento, quanto mobilizam suas vozes na terra brasileira, estão sendo brasileiros, estão sendo Pindorama” (PROJETO ARARIBA, 2014, p. 174).

Esta letra se refere aos Tupi como a única etnia existente ou a que prevalece, associando a história anterior à colonização de forma simplificada, homogênea e infantil, características essas que se estendem a esses povos. As representações trazidas nas canções podem ser facilmente identificadas com os discursos cotidianos de nossa sociedade, reforçando estereótipos. As interpretações estão fundamentadas em percepções construídas socialmente e calcadas em preconceitos, crença e idealizações e não na reflexão sobre a realidade que envolve as culturas indígenas (BARBOSA, 2011, p. 13).

No segundo título "Os índios de hoje", o livro rompe com a concepção de uma única etnia indígena, porém de modo resumido, apenas citando números sem aprofundar nos 
aspectos que diferenciam esses povos: “[...] os índios nunca formaram um único povo. Hoje, segundo dados do instituto Socioambiental (ISA), são 238 culturas diferentes espalhadas pelo território brasileiro" (PROJETO ARARIBA, 2014, p. 173). A principal marca do mundo indígena é a diversidade de povos, culturas, línguas, civilizações, religiões, economias e uma multiplicidade de formas de vida coletiva e individual que não foram abordadas, reforçando nosso quase total desconhecimento sobre os diferentes grupos e etnias que estão presentes no território brasileiro.

A diversidade cultural é tratada a partir da multiplicidade das línguas faladas pelos indígenas, contudo de forma concisa: "A diversidade cultural que caracteriza os povos indígenas pode ser medida pelo número de línguas faladas por eles: são mais de 180" (PROJETO ARARIBA, 2014, p. 173). Sem a reflexão proposta no PCN:

Conhecer a existência do uso de outras línguas diferentes da Língua portuguesa, idioma oficial, significa não só ampliação de horizontes como também compreensão da complexidade do país. A escola tem a possibilidade de trabalhar com esse panorama rico e complexo, referindo-se à existência, estrutura e uso de centenas de línguas. Pode, com isso, além de oferecer informações e possibilitar reflexões sobre a língua materna, promover a compreensão de como se constituem identidades e singularidades de diferentes povos e etnias [...] (BRASIL, 1997, p. 154).

Outra aproximação constante no imaginário social e presente no livro didático é a do índio com a natureza. "Os povos indígenas desenvolveram um conhecimento único da natureza. Eles conhecem propriedades medicinais e cosméticas de raízes, sementes, folhas, frutos, cascas de árvores etc.” (PROJETO ARARIBA, 2014, p. 173). Essa relação “adquirida no final dos anos 80 pelo par índio/natureza precisa ser reconsiderada, [...] porque está assentada sobre um equívoco: o de que o reconhecimento dos direitos indígenas se faz em decorrência de seu valor ecológico" (GRUPIONI, 1994, p. 23).

As relações aqui estabelecidas demonstram como os conceitos incorporados no livro didático não conseguem estabelecer novas visões acerca da compreensão da diferença. A narrativa presente neste documento reforça formulações de que os índios não têm passado ou que representam um estado primitivo do desenvolvimento humano, de que o contato com os europeus levou a uma aculturação que descaracterizou e fez desaparecer suas expressões culturais e que os índios preservam a natureza porque são parte dela. Algo bem diferente das novas propostas educacionais de valorização das diversidades culturais que pretende libertarse de percepções estereotipadas, preconceituosas e quase sempre empobrecidas, com a finalidade de abrir-se para novas maneiras de olhar e entender o mundo, os outros e a si próprio (SILVA; GRUPIONI, 1995, p. 19). 
Seguindo as mesmas desarmonias, é possível identificar uma segunda visão propagada no livro didático que surgiu com a chegada dos portugueses. "A compreensão sustentada pela visão do índio cruel, bárbaro, canibal, animal, selvagem, preguiçoso, traiçoeiro e tantos outros adjetivos e denominações negativos" (SILVA; GRUPIONI, 1995, p. 20). Essas "denominações e adjetivos eram para justificar suas práticas de massacre como autodefesa e defesa dos interesses da Coroa" (SILVA; GRUPIONI, 1995, p. 19),

As aldeias ligavam-se entre si por alianças, estabelecidas conforme afinidades e relações de parentesco. Tais alianças variavam com o tempo: os amigos de hoje poderiam ser os inimigos de amanhã. [...] A guerra, um comportamento cultural básico e constante na vida dos Tupi, servia, sobretudo, para vingar os parentes mortos pelos inimigos. O maior triunfo resumia-se em matar e comer o oponente capturado na luta. O prisioneiro, conduzido à aldeia inimiga, integrava-se à rotina do lugar até ser devorado em um ritual que reunia os membros da aldeia e seus aliados (PROJETO ARARIBA, 2014, p. 174).

Ao aplicar conceitos específicos de uma etnia indígena sob o título "Cultura", pressupõe-se que essa prática era comum a todas as tribos aqui presentes. Mais uma vez o livro concebe generalizações, apontando primeiro um indígena indefeso, dominado e disseminado pela presença dos europeus e depois um indígena selvagem, desprovido de humanidade e razão. É notável perceber como o documento analisado, nos dias atuais, difunde interpretações formuladas no século XVI e debates que se intensificam no final do século XVIII e início do XIX, com a retomada dos estudos das crônicas dos viajantes. Perpetuar esse imaginário impossibilita o aluno de entender a presença indígena no presente e no futuro e de compreender uma sociedade multiétnica.

Como síntese das duas visões é sugerida a atividade de "compreender um texto" a partir do artigo "A cordialidade dos tupinambás":

A relação fundamental que, em diferentes momentos, se estabeleceu entre os índios e os franceses que acompanhavam Jean de Léry foi de aliança. [...] Essa necessidade de sobrevivência associada à receptividade dos índios, contribuiu em muito para uma caracterização que enfatizava elementos de 'humanidade' nos 'selvagens'. Assim, a aceitação do 'outro', em face das limitações, poderia ser relacionada à necessidade de convivência e ao estabelecimento de uma espécie de 'acordo' social entre as duas culturas. [...] Se, por um lado, não havia como considerar índios civilizados, já que este conceito estava intimamente relacionado à vida urbana, poderiam- a partir de algumas observações - ser vistos como dotados de traços de humanidade. Algumas das consideração feitas por Léry sinalizam para a aceitação parcial da condição humana dos indígenas por alguns europeus e, particularmente, de parte deste grupo de franceses. [...] Apesar da descrição de contatos cordiais entre o grupo de Léry e os índios, não podemos desconsiderar as observações do cronista a respeito de sua 'bestialidade' ou mesmo da periculosidade que, muitas vezes representavam. [...] Jean de Léry destaca que havia tribos que se mostravam muito hostis à presença estrangeira, como na referência que faz à 'inimizade entre 
Margáias e franceses, muito bem dissimulada de parte a parte." (PROJETO ARARIBA, 2014, p. 175).

Como se pode observar, em um único texto reuni-se as duas visões do indígena a partir do referencial de Léry. $\mathrm{O}$ artigo descreve a impressão de um francês sobre povos nativos. Na mentalidade do século XVI as interpretações se davam "[...] por princípios de semelhança e de acordo com um código de correspondências estabelecidas por proximidades, comparações” (BELLUZZO, 1994, p. 48). Dessa maneira não é viável a análise de um texto com peculiaridades históricas na descrição dos indígenas ser apresentado ao aluno sem uma reflexão a respeito das produções do século XVI e o conceito de alteridade.

Essa distância entre o material oferecido e sua inserção no momento histórico de produção é encontrada também nas imagens presente no livro que pesquisamos como podemos ver nas figuras 1 e 2 .

Figura 1

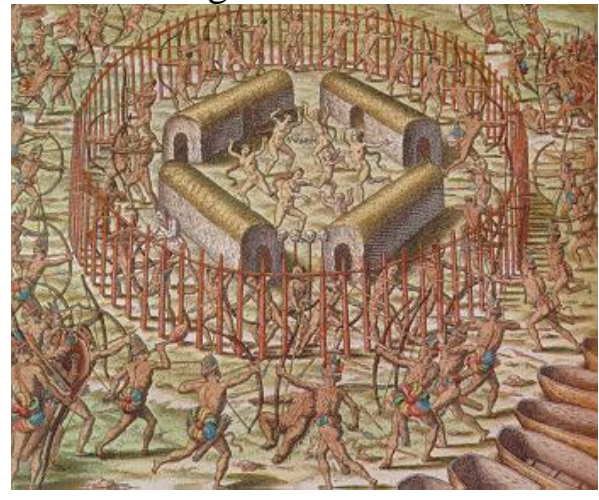

Ataque tupiniquim a uma aldeia Tupinambá. Gravura colorizada de Theodore de Bry, de 1562, para a narrativa de Hans Stadem. Arquivo Histórico da Marinha Francesa, Vincennes, França. Os paus da cerca foram desenhados assim para mostrar como seria o interior da aldeia (PROJETO ARARIBA, 2014, p. 174).

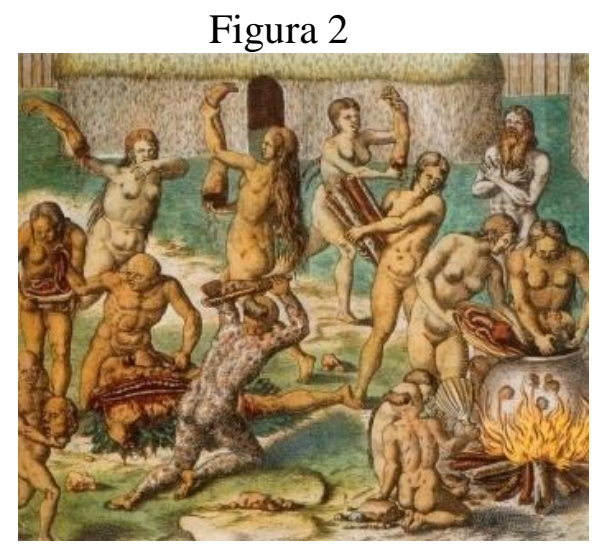

Gravura de Theodore de Bryrepresentando Tupinambá desmembrando e cozinhando o inimigo, durante um ritual antropofágico, 1562. Arquivo Histórico da Marinha Francesa, Vincennes, França (PROJETO ARARIBA, 2014, p. 175). 
Na sessão "Em Foco" são trabalhadas duas gravuras de Theodor de Bry colorizadas. As imagens são ilustrativas, não há nenhuma explicação, como, por exemplo, o momento histórico em que foi produzida, quem é Theodor de Bry, em que obra foram publicada e o porquê se utilizou uma imagem colorida ao invés da reprodução das imagens originais.

O que encontramos no final da referência da segunda imagem é: "a antropofagia foi um dos costumes indígenas que mais impressionaram e chocaram os europeus. Seguida da questão: "Que características culturais dos Tupis foram representadas nas imagens?" (PROJETO ARARIBA, 2014, p. 173). O trabalho com imagem proposto pelo livro didático é totalmente descontextualizado, tendo em vista que as duas imagens foram produzidas no século XVI e que os homens representados não eram indígenas, muito menos tupis.

Como é possível observar na figura 1, os “indígenas" representados usam cocar, característica dos nativos encontrados na atual região da Flórida (EUA), sendo essa uma marca das imagens de De Bry, reprodução de um modelo de "índio" para todas as regiões do Novo Mundo já que sua obra é uma compilação de imagens e crônicas de diferentes regiões do Novo Mundo.

Na figura 2, assim como na figura 1, é nítida a identificação dos "indígenas" com características físicas europeias: barba, cabelos ondulados e alguns homens calvos, seus corpos tem o padrão renascentista. Como é possível, então, uma questão que vincule essa imagem a "características culturais dos Tupis", supondo que aquilo que está ilustrado seja uma representação do real quando é perceptível que estas imagens dizem muito mais sobre a Europa do que sobre as populações aqui encontradas. Essa aproximação contrasta com todas as propostas educacionais que pretendem desconstruir estereótipos dos indígenas vistos como primitivos, selvagens e com características homogêneas, "estando em descompasso com as pesquisas e estudos que foram e são realizados a respeito das culturas indígenas em nosso país” (BARBOSA, 2011, p. 52).

Ilustrando o texto "A cordialidade dos Tupinambás", estão as figuras 3 e 4 . As duas imagens também não se relacionam com o texto e, assim como as imagens 1 e 2, o exercício indicado pelo livro é: "Observe as imagens que ilustram a obra de Jean de Léry e identifique as características da cultura Tupinambá que elas representam”.

Figura 3 


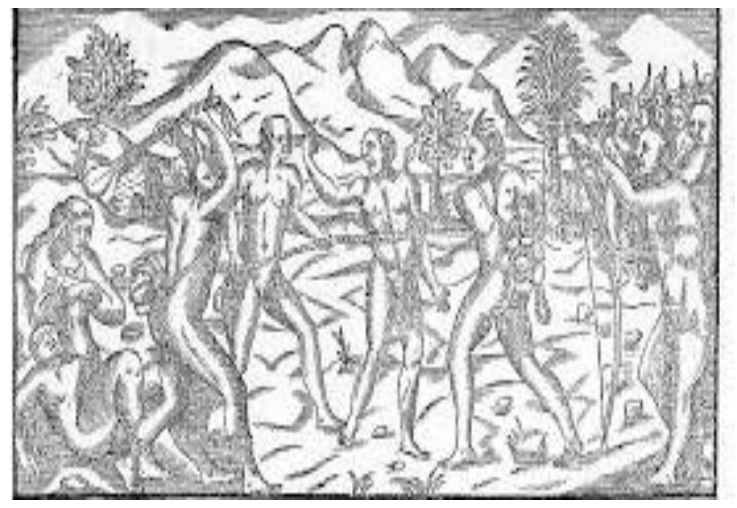

Representação de combate entre Tupinambá e Maracajá. Ilustração da obra Viagem à terra do Brasil, de Jean de Léry, edição de 1580. Fundação Biblioteca Nacional, Rio de Janeiro (PROJETO ARARIBA, 2014, p. 176).

Figura 4

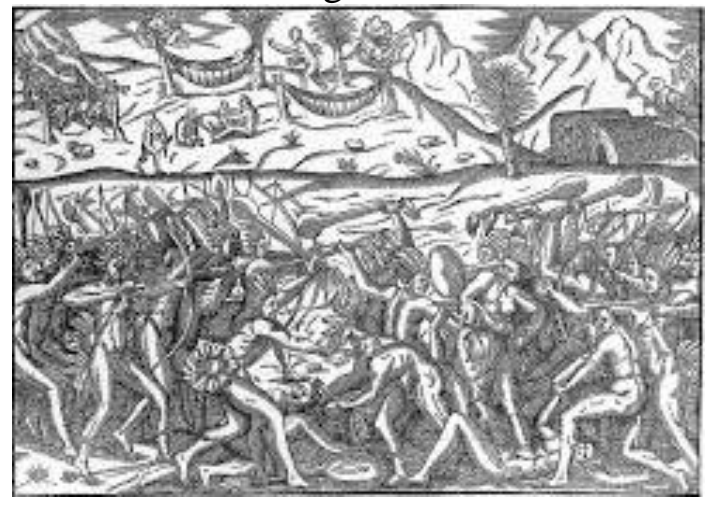

Representação de indígenas. Ilustração da obra Viagem à terra do Brasil, de Jean de Léry, edição de 1594. Biblioteca John Carter Brownda Universidade Brown, Providence, Estados Unidos (PROJETO ARARIBA, 2014, p. 177).

Novamente é notório as características físicas europeias atribuídas aos indígenas nas figuras. Outra lacuna que também se mantém é não apresentar as especificidades da obra de onde foram retiradas as imagens. Assim como, explica Ana Maria de Moraes Belluzzo ao trabalhar com as imagens presentes na obra de Léry:

A obra de Jean de Léry exemplifica o projeto enciclopédico do século XVI. Está referida á obra de Thevet em sua origem. A história de uma viagem à terra do Brasil, também chamada América é editada cerca de vinte anos depois da volta do missionário calvinista do Brasil, para onde teria se dirigido em 1556, por empresa de Coligny. Desejava revelar desvio de Villegaignon do evangelho e refutar o que afirmara André Thevet, cosmógrafo do rei e representante da Igreja católica franciscana (BELLUZZO, 1994, p. 30).

Dessa maneira, é plausível perceber que as figuras escolhidas não possibilitam ao aluno extrair características culturais dos povos Tupinambás, uma vez que, essas foram produzidas a partir de "preceitos clássicos, [onde Jean de Léry] irá recortá-las de sua realidade e transportá-las para o mundo ideal das relações proporcionais. Desse modo, o índio passa a ser mostrado como universalidade humana" (BELLUZZO, 1994, p. 31). 
Utilizar imagens que falam a respeito do índio de forma isolada e como testemunha do passado não fornece aos alunos instrumentos para que ele possa refletir e discutir sobre as construções sociais que se perpetuam há vários séculos.

Assim sendo, o livro didático analisado representa os grupos indígenas com imagens contraditórias, que simplificam a questão, induzindo o aluno à incapacidade de compreender um "outro" que é diferente. Em vista disso, podemos identificar que o livro didático do $7^{\circ}$ ano, projeto Araribá, continua a trabalhar com formulações esquemáticas, ignorando as pesquisas feitas pela história e pela antropologia no conhecimento do "outro". Se mostra deficiente ao tratar a diversidade étnica e cultural existente no Brasil, como propõe o tema transversal Pluralidade Cultural dos PCN's e a Lei $n^{\circ} 11.645 / 08$, impossibilitando o projeto de "[...] eliminar conceitos errados, culturalmente disseminados, acerca de povos e grupos humanos que constituem o Brasil" e a "[...] possibilidade de desenvolvimento de valores básicos para o exercício da cidadania, voltados para o respeito do outro e a si mesmo[...]" (BRASIL, 1997, p. 157), e, por fim, da “[...] possibilidade de que os alunos compreendam, respeitem e valorizem a diversidade sociocultural e a convivência solidária em uma sociedade democrática" (BRASIL, 1997, p. 147).

\section{Considerações Finais}

A partir da análise do material didático escolhido, o que podemos constatar é que em diversos trechos do livro as referidas propostas governamentais são ignoradas, mesmo que nomenclaturas sejam modificadas, os conceitos trabalhados permanecem ainda preconceituosos, trabalhando os povos indígenas a partir da colonização e desconsiderando suas experiências anteriores, como se houvessem apenas dois grandes povos, Tupis e Tupinambás, que são representados por imagens e textos do século XVI, situando-os como agentes pacíficos da colonização. Concluindo-se, dessa forma, o insucesso da aplicação das orientações do tema transversal Pluralidade Cultural e da Lei 11.645/08 no livro didático aqui estudado, o que gera uma perpetuação de conceitos errôneos nas escolas. Demonstrando como o ensino escolar permanece distante do ensino acadêmico que, no Brasil.

Como se pôde observar, investir na aproximação das pesquisas acadêmicas com o ensino escolar é fator primordial para que se alcance uma educação de qualidade capaz de romper com discriminações que habitam o imaginário social. O tema transversal Pluralidade Cultural, assim como a Lei 10.639/03, foram escritos visando atender expectativas internacionais de valorização da diversidade e eliminação do preconceito. Essa mudança na 
historiografia transforma a maneira de se pensar o "outro", sendo essa perspectiva que sustenta os textos educacionais aqui estudados.

Dessa maneira, percebemos que a metodologia encontrada no livro didático não conseguiu ainda alcançar as leis educacionais da década de 60, trabalhando ainda com uma história de tradição iluminista, privilegiando as ideias e manifestações eruditas em que "civilização" assumiu lugar de destaque.

\section{Referências}

\section{I - Fontes}

PROJETO ARARIBÁ: história/organizadora Editora Moderna; obra coletiva concebida, desenvolvida e produzida pela Editora Moderna; editora responsável Maria Raquel Apolinário. $3^{\circ}$ Ed. São Paulo: Moderna, 2010. Componente curricular: História. Ensino Fundamental. PNLD 2014/2015/2016-FNDE Ministério da Educação.

\section{II - Bibliografia}

ABREU, Martha; SOIHET, Raquel (Org.) Ensino de história: conceitos, temáticas e metodologia. Rio de Janeiro: Casa da Palavra, 2003.

ALMEIDA, Maria Regina Celestino. Populações indígenas e Estados Nacionais latinoamericanos: novas abordagens historiográficas. IN AZEVEDO, Cecília; RAMINELLI, Ronald. (Org.) História das Américas novas perspectivas. Rio de Janeiro: Editora FGV, 2011.

BARBOSA, Lucia Maria de Assunção. Relações étnico-raciais em contexto escolar; fundamentos, representações e ações. São Carlos: EDUFSCAR, 2011.

BECHIER, Rosiane Ribeiro; SILVA, Cristiani Bereta. Livros didáticos como textos de memória: notas sobre narrativas da imigração alemã em livros didáticos de história regionais. Revista História da Educação, 2019, v.23

BELLUZZO, Ana Maria de Moraes. A lógica das imagens e os habitantes do Novo Mundo. IN: GRUPIONi, L.D.B. (Org.) Índios no Brasil. Brasília: Ministério da Educação e do Desporto, 1994.

BIGELI, Maria Cristina Floriano. Ensino de história e cultura indígena: os discursos do currículo São Paulo faz escola (2014-2017) e dos docentes de história. Tese de Doutorado, Universidade Estadual Paulista (UNESP), Faculdade de Educação, Marília, 2018.

BITTENCOURT, Circe Maria Fernandes. Ensino de história; fundamentos e métodos. São Paulo: Cortez, 2011.

BRASIL. Constituição da República Federativa do Brasil, 1988. Brasília: Senado Federal/ Centro Gráfico, 1988. 
Diretrizes Curriculares Nacionais para a educação das relações étnico-raciais e para o ensino da história afro-brasileira e africana. Brasília: SECAD/ME, 2004.

Lei de Diretrizes e Bases da Educação Nacional, Lei n 9.394, 20 de dezembro de 1996.

Lei $\mathbf{n}^{\circ} 11.645$ de 10 de março de 2008. Disponível em www.planalto.gov.br/ccivil_03/_Ato2007-2010/2008/Lei/L11645.htm. Acessado em $\underline{01 / 09 / 2018 .}$.

Parâmetros Curriculares Nacionais: pluralidade cultural. Brasília, 1997.

Plano Nacional das Diretrizes Curriculares Nacionais para a educação das relações étnico-raciais e para o ensino de história e cultura afro-brasileira e africana. Brasília: Secad/Seppir, 2009.

BRUM, Meline de Barros; VOGT, Olgário Paulo. Escravidão e negros em livros didáticos de história. Revista Aedos, v. 8, n. 18, Ago. 2016.

FONTENELE, Zilfran Varela; SILVA, Isaíde Bandeira da. A inclusão da história e cultura afro brasileira e indígena no livro didático de história. XXVIII Simpósio nacional de História, Florianópolis:2015.

FRANCO, Gilmara Yoshihara; TRUBILIANO, Carlos Alexandre Barros. O Livro didático de História e a questão da identidade nacional brasileira ao longo do período republicano: a fronteira entre rupturas e continuidades. Fronteiras: Revista de História, Dourados-MS, v.17, n.30, Jul-Dez 2015.

FREITAS, Itamar. Reformas educacionais e os currículos nacionais para o ensino de história no Brasil republicano (1931/2009). Cadernos de história da Educação, Uberlândia, nº 1, v.12, 2013.

GARRIDO, Mírian Cristina de Moura. Livro Didático, movimento Negro e PNLD: uma proposta de pesquisa. Anais do XIX Encontro Regional de História: Poder, Violência e Exclusão. ANPUH/SP USP, set. 2008.

GOMES, Nilma Lino Diversidade étnico-racial, inclusão e equidade na educação brasileira: desafios, políticas e práticas. In: GOMES, Nilma Lino(Org.) Um olhar além das fronteiras: educação e relações raciais. Belo Horizonte: Autêntica, 2007.

GRUPIONI, Luis Donisete Benzi (Org.) A questão indígena na sala de aula subsídios para professores de 1/ e $2^{\circ}$ graus. Brasília: MEC?MARI/UNESCO, 1995.

do Desporto, 1994.

(Org.) Índio no Brasil. Brasília: Ministério da Educação e

LUCA, Tania Regina de; MIRANDA, Sonia Regina. O livro didático hoje: um panorama a partir do PNLD. Revista Brasileira de História, São Paulo, v. 24, n. 48, 2004. 
MUNAKATA, Kazumi. O livro didático como mercadoria. Revista Pro-Posições. UNICAMP, Campinas, v. 23, n. 3, p. 51-66, set./dez. 2012.

NETO, José Alves de Freitas. A transversalidade e a renovação no ensino de história. IN: KARNAL, Leandro. História na sala de aula: conceitos, práticas e propostas. São Paulo: Editora Contexto, 2003.

SCHMIDT, Maria Auxiliadora; CAINELLI, Marlene. Ensinar História. São Paulo: Editora Scipione, 2010.

SILVA, Aracy Lopes; GRUPIONI, Luis Donisete Benzi(org.) A questão indígena na sala de aula: subsídios para professores de $1^{\circ}$ e $2^{\circ}$ graus. Brasília: MEC/MARI/UNESCO, 1995.

SILVA, Marco Antônio. A Fetichização do Livro Didático no Brasil. Revista Educação \& Realidade / UFRGS, Porto Alegre, v. 37, n. 3, 2012.

SILVA, Maurício; PEREIRA, Márcia Percurso da lei 10639/03 e o ensino de história e cultura africana no Brasil; antecedentes, desdobramentos e caminhos. Publicação do Programa de Pós-Graduação em História da Universidade de Brasília. n²2. Brasília, 2013.

SIMAN, Lana Mara de Castro. Representações e memórias sociais compartilhadas: desafio para os processos de ensino e aprendizagem da história. Cad. Cedes, Campinas, n. 67, vol. 25, set/dez., 2005, pp. 348-364. 